\title{
Synthesis of New Quaternary Ammonium Salts with a Terpene Function and Evaluation of their Fungicidal and Herbicidal Activities
}

\author{
Krzysztof Żelechowski, Mirosław Gucma, W. Marek Gołębiewski, * \\ Maria Krawczyk and Alicja Katarzyna Michalczyk \\ Łukasiewicz Research Network - Institute of Industrial Organic Chemistry, Annopol 6, 03-236 Warsaw, Poland \\ * Corresponding author: E-mail: golebiewski@ipo.waw.pl \\ Telephone: 4822811 1231; fax: 48228110799
}

Received: 09-18-2019

\begin{abstract}
A series of new quaternary ammonium salts (QASs) containing a terpenoid moiety derived from perillyl alcohol, citronellol, and geraniol was synthesized. Structures of all novel compounds were confirmed by spectral methods and elemental analyses. Fungicidal activity of the obtained compounds against six plant pathogens, against four fungi destroying wood and technical materials as well as herbicidal activity against ten species of temperate climate weeds has been examined. Several salts showed a higher antifungal and herbicidal activity than activity of the reference compounds.
\end{abstract}

Keywords: Ammonium salts; fungicides; herbicidal activity; NMR spectroscopy; terpenoids

\section{Introduction}

Quaternary ammonium salts (QASs) are cationic surfactants widely used to combat microorganisms in clinical and industrial applications for the disinfection of surfaces. They are amphoteric compounds containing a quaternary nitrogen atom which is bound to at least one major hydrophobic substituent, such as alkyl, and an anion. The ability to reduce the surface tension facilitates adsorption of the cation on the cell surface and penetration of hydrophobic residues of microbicidal action to the cell membrane of microorganisms. QASs are also used as inter alia fabric softeners, ${ }^{1,2}$ antistatic and wood protection agents. ${ }^{3}$ It was found that salts with alkyl chain length of $n=12-14$ had the greatest activity against Gram-positive bacteria and yeasts, ${ }^{4}$ while salts with $n=14-16$, had a maximum activity against Gram-negative bacteria. QASs with aromatic spacers and alkyl groups of different length and different number of charged nitrogen atoms were examined. ${ }^{5}$ The structure-activity relationship (SAR) and modes of action of bis QASs have been discussed. ${ }^{6}$

Few biocides can fight both fungi and insects. These agrochemicals include quaternary ammonium salts, such as didecyldimethylammonium chloride (DDAC) and benzalkonium chlorides (BAC), having a low toxicity to warm-blooded organisms. ${ }^{7}$
Antimicrobial activity of quaternary ammonium pyridinium (QPy) salts was examined addressing the problem of increasing resistance of microorganisms caused by misuses of QASs. ${ }^{8} \mathrm{pH}$ sensitive QPy salts were prepared which activity was controlled by adjusting $\mathrm{pH}$ to low values. ${ }^{9}$ QASs containing other heterocyclic systems such as benzofuroxan, ${ }^{10}$ pyridobenzodiazepine were also prepared. ${ }^{11}$

Another approach to avoid microbial resistance was an application of gemini QASs (double head - double tail type). ${ }^{12,13}$

An effect of organic counterions on antibacterial activity was discussed. ${ }^{14}$

Conjugates of QASs with steroids were prepared and shown to exhibit a broad spectrum of antimicrobial activity. ${ }^{15}$

Antimicrobial polymers were developed to increase efficiency, selectivity and durability of the low molecular weight agents. ${ }^{16}$ Another examples were QASs immobilized on dendrimers ${ }^{17}$ hydroxy QASs as components of polyurethane foams ${ }^{18}$ or natural modified polymers (chitosan). ${ }^{19}$

Another new group of organic biocides were ionic liquids: pyridinium, ${ }^{20}$ imidazolium, ${ }^{21}$ ammonium and triazolium. ${ }^{22}$ 
Terpenes are regarded as defensive compounds in plants, offering them protection against herbivores. ${ }^{23}$ Terpenes are used in control of termites and other urban pests. ${ }^{24,25}$ Terpenes as residual plant material are used also in composite products resistant to termite degradation. ${ }^{26}$ Terpene-baited traps are applied to control the pine sawyer beetle. ${ }^{27}$ Hinokitiol, a natural monoterpenoid found in the wood of trees in the family Cupressaceae, displays insecticidal and fungicidal activities against wood-rotting fungi. ${ }^{28}$ Essential oils isolated from the leaves and twigs of Litsea acutivena plant show antimicrobial and anti-wood-decay fungal activities. ${ }^{29}$

Application of QASs in dentistry and oral care was reviewed. ${ }^{30}$ Some QASs inhibited humane androgenic and estrogenic receptors. ${ }^{31}$

The antimycobacterial activity of quaternary ammonium salts increased with the presence of the terpene fragment in the molecule. ${ }^{32}$

QASs with a carbamate group were incorporated into polyurethane coatings via crosslinking with terpene-based polyol and polyisocyanate and showed antimicrobial activity. ${ }^{33}$

QASs are readily biodegradable involving mainly microorganisms of Pseudomonas genera. ${ }^{34}$ Ease of QASs biodegradation decreases with increasing length and the number of alkyl chains. ${ }^{7}$

Recently herbicidal activity of QASs was reported. These compounds were synthesized from aminoacetanilides prepared from known herbicides alachlor and acetochlor. $^{35}$

Application of Inverse QSAR/QSPR analysis for pesticides structures generation has been recently presented. The authors described the relations of pesticide structures to their $n$-octanol-water partition coefficients affording potential new pesticide structures. ${ }^{36}$

Molecular docking analysis including several known targets indicated that the $\mathrm{N}$-myristoyltransferase is a likely site of interaction with fungicides. ${ }^{37}$

These results induced us to prepare a series of ammonium salts containing a terpene-derived moiety and to test their biological activity which was disclosed in our patent application. ${ }^{38}$ The rapid emergence of resistance in pathogenic organisms justifies the search for new, selectively acting preparations. The proposed new ammonium salts with a terpenoid fragment may prove to be effective, readily biodegradable wood preservatives.

\section{Experimental Section}

\section{1. Materials and Physical Measurements}

Reagent grade chemicals were used without further purification unless otherwise noted. Spectra were obtained as follows: ${ }^{1} \mathrm{H}$ and ${ }^{13} \mathrm{C}$ NMR spectra on Varian 300 UNITY plus 300 spectrometer in deuterated chloroform using TMS as internal standard. Chemical shifts are given in ppm $(\delta)$ relative to tetramethylsilane (TMS) as an internal standard, coupling constants are reported in Hz. Flash chromatography was carried out using silica gel S 230-400 mesh (Merck) and hexane-ethyl acetate mixtures as eluents. $\log P$ was calculated using EPI Suite ${ }^{\mathrm{TM}} 4.11$ Estimation Program Interface developed by Syracuse Research Corp., Syracuse, NY, USA. Elemental analyses (C, H, N) were conducted using the Elemental Analyser XBO, their results were found to be in good agreement $( \pm 0.3 \%)$ with the calculated values.

\section{2. Chemistry}

1-(Bromomethyl)-4-(prope-1-en-2-yl)cyclohexene (2)

Bromide 2 was prepared by the published method and its ${ }^{1} \mathrm{H}$ NMR spectrum was found to be identical with the one described. ${ }^{39}$

\section{1-(Chloromethyl)-4-(prop-1-en-2-yl)cyclohexene (3)}

Chloride 3 was prepared by the published method and its ${ }^{1} \mathrm{H}$ NMR spectrum was found to be identical with the one described. ${ }^{40}$

\section{General Procedure for Preparation of Quaternary Am- monium Bromides 4a-e, 7a-e, 10a-e}

Bromide $2(1.0 \mathrm{mmol})$ was placed in the flask, then anhydrous benzene and tertiary amine (1.1-1.3 mmol) were introduced. The reaction was carried out at reflux for 4-6 hours and stirred overnight at room temperature. The reaction mixture was evaporated and after dissolving the residue in a small amount of benzene the product was precipitated with ethyl ether. The operation was repeated depending on the derivative from two to three times. Yields ranged from $70 \%$ for reactions with long chain amines up to $98 \%$ for shorter chain amines.

(4R)- $N, N$-Dimethyl- $N$ - $\{[4$-(prop-1-en-2-yl)cyclohex-1en-1-yl]methyl octylammonium Bromide (4a)

This salt was prepared as a yellowish wax $(0.354 \mathrm{~g}$, 95\%). ${ }^{1} \mathrm{H}$ NMR (300 MHz, $\left.\mathrm{CDCl}_{3}\right) \delta 6.31(\mathrm{~s}, 1 \mathrm{H}, \mathrm{H} 3), 4.74$ $(\mathrm{d}, J=24 \mathrm{~Hz}, 2 \mathrm{H}, \mathrm{H} 9), 4.24(\mathrm{~s}, 2 \mathrm{H}, \mathrm{H} 1), 3.51-3.48(\mathrm{~m}, 2 \mathrm{H})$, $3.30\left(\mathrm{~s}, 6 \mathrm{H}, \mathrm{Me}_{2} \mathrm{~N}\right), 2.63(\mathrm{bs}, 1 \mathrm{H}), 2.35-2.05(\mathrm{~m}, 5 \mathrm{H}), 1.74-$ $1.65(\mathrm{~m}, 2 \mathrm{H}), 1.74(\mathrm{~s}, 3 \mathrm{H}, \mathrm{H} 10), 1.58-1.46(\mathrm{~m}, 1 \mathrm{H}), 1.4-$ $1.12(\mathrm{~m}, 10 \mathrm{H}), 0.88\left(\mathrm{t}, J=6 \mathrm{~Hz}, 3 \mathrm{H}, \mathrm{H}_{3} \mathrm{CCH}_{2}\right) ;{ }^{13} \mathrm{C} \mathrm{NMR}$ $\left(75.5 \mathrm{MHz}, \mathrm{CDCl}_{3}\right) \delta 148.0,139.4$. 126.0, 109.0, 70.2, 64.0, 50.5, 50.4, 39.3, 31.3, 30.8, 30.3, 28.9, 28.8, 27.0, 26.0, 22.6, 22.3, 20.5, 13.8; Anal. Calcd for $\mathrm{C}_{20} \mathrm{H}_{38} \mathrm{BrN}$ : C, 64.50; H, $10.28 ; \mathrm{N}, 3.70$. Found: C, 64.41; H, 10.39; N, 3.64.

(4R)- $N, N$-Dimethyl- $N$ - $\{[4$-(prop-1-en-2-yl)cyclohex-1en-1-yl]methyl\}decylammonium Bromide (4b)

This salt was similarly prepared as above as a yellowish wax $(0.368 \mathrm{~g}, 92 \%) .{ }^{1} \mathrm{H}$ NMR $\left(300 \mathrm{MHz}, \mathrm{CDCl}_{3}\right) \delta 6.32$ (s, 1H, H3), 4.77 (s, H, H9a), 4.69 (s, H, H9a), 4.25 (s, 2H, $\mathrm{H} 1), 3.50(\mathrm{~m}, 2 \mathrm{H}), 3.30\left(\mathrm{~s}, 6 \mathrm{H}, \mathrm{Me}_{2} \mathrm{~N}\right), 2.38-2.05(\mathrm{~m}, 5 \mathrm{H})$, $1.87-1.74(\mathrm{~m}, 2 \mathrm{H}), 1.74(\mathrm{~s}, 3 \mathrm{H}, \mathrm{H} 10), 1.56-1.47(\mathrm{~m}, 1 \mathrm{H})$, 
$1.40-1.23(\mathrm{~m}, 14 \mathrm{H}), 0.88(\mathrm{t}, J=6.9 \mathrm{~Hz}, 3 \mathrm{H}) ;{ }^{13} \mathrm{C} \mathrm{NMR}$ $\left(75.5 \mathrm{MHz}, \mathrm{CDCl}_{3}\right) \delta 147.9,139.2,125.9,108.9,70.0,63.8$, 50.3, 50.2, 39.1, 31.4, 30.6, 29.0, 28.8, 26.8, 25.9, 22.5, 22.2, 20.3, 13.6: Anal. Calcd for $\mathrm{C}_{22} \mathrm{H}_{42} \mathrm{BrN}$ : C, 65.98; H, 10.57; N, 3.50. Found: C, 66.05; H, 10.67; N, 3.38.

(4R)-N,N-Dimethyl- $N$ - $\{[4$-(prop-1-en-2-yl)cyclohex-1en-1-yl]methyl\}dodecylammonium Bromide (4c)

This salt was similarly prepared as the salt $\mathbf{4 a}$ as a yellowish wax (0.386 g, 90\%). ${ }^{1} \mathrm{H}$ NMR $\left(300 \mathrm{MHz}, \mathrm{CDCl}_{3}\right)$ $\delta 6.32(\mathrm{~s}, 1 \mathrm{H}, \mathrm{H} 3), 4.77$ (s, 1H, H9a), 4.69 (s, 1H, H9a), $4.29(\mathrm{~s}, 2 \mathrm{H}, \mathrm{H1}), 3.53\left(\mathrm{~m}, 2 \mathrm{H}, \mathrm{CH}_{2} \mathrm{~N}\right), 3.32\left(\mathrm{~s}, 6 \mathrm{H}, \mathrm{Me}_{2} \mathrm{~N}\right)$, 2.38-2.25 (m, 2H, H4), 2.25-2.05 (m, 3H), 1.87-1.72 (m, $3 \mathrm{H}), 1.74(\mathrm{~s}, 3 \mathrm{H}, \mathrm{H} 10), 1.58-1.45(\mathrm{~m}, 1 \mathrm{H}), 1.42-1.20(\mathrm{~m}$, $18 \mathrm{H}), 0.88(\mathrm{t}, J=6.6 \mathrm{~Hz}, 3 \mathrm{H}) ;{ }^{13} \mathrm{CNMR}\left(75.5 \mathrm{MHz}, \mathrm{CDCl}_{3}\right)$ $\delta 148.0,139.4,126.0,109.0,70.2,63.9,50.5,50.4,39.3$, $31.6,30.8,30.3,29.3$ (2C), 29.2, 29.1, 29.0, 29.0, 27.0, 26.1, 22.7, 22.4, 20.5, 13.8; Anal. Calcd for $\mathrm{C}_{24} \mathrm{H}_{46} \mathrm{BrN}$ : C, 67.27; H, 10. 82; N, 3.27. Found: C, 67.51; H, 10.71; N, 3.17.

(4R)- $N, N$-Dimethyl- $N$ - $\{[4$-(prop-1-en-2-yl)cyclohex-1en-1-yl]methyl\}tetradecylammonium Bromide (4d)

This salt was similarly prepared as the salt $\mathbf{4 a}$ as a wax $(0.343 \mathrm{~g}, 75 \%) .{ }^{1} \mathrm{H}$ NMR $\left(300 \mathrm{MHz}, \mathrm{CDCl}_{3}\right) \delta 6.32$ (s, 1H, H3), 4.77 (s, 1H, H9a), 4.69 (s, 1H, H9b), 4.28 (s, 2H, $\mathrm{H} 1), 3.53\left(\mathrm{~m}, \mathrm{CH}_{2} \mathrm{~N}\right), 3.32\left(\mathrm{~s}, 6 \mathrm{H}, \mathrm{Me}_{2} \mathrm{~N}\right), 2.38-2.22(\mathrm{~m}$, $2 \mathrm{H}, \mathrm{H} 4), 2.25-2.05(\mathrm{~m}, 3 \mathrm{H}), 1.87-1.72(\mathrm{~m}, 2 \mathrm{H}), 1.74(\mathrm{~s}$, $3 \mathrm{H}, \mathrm{H} 10), 1.58-1.45(\mathrm{~m}, 1 \mathrm{H}) 1.40-1.20(\mathrm{~m}, 23 \mathrm{H}), 0.88(\mathrm{t}, J$ $=6.6 \mathrm{~Hz}, 3 \mathrm{H}) ;{ }^{13} \mathrm{C} \mathrm{NMR}\left(75.5 \mathrm{MHz}, \mathrm{CDCl}_{3}\right) \delta 147.9,139.4$, $126.0,109.0,70.1,63.9,50.4,50.3,39.2,31.5,30.7,30.2$, $29.3,29.3,29.3,29.1,29.1,29.0,28.9,26.9,26.7,26.0,25.6$, 22.6, 22.3, 20.4, 13.8; Anal. Calcd for $\mathrm{C}_{26} \mathrm{H}_{50} \mathrm{BrN}$ : C, 68.39; H, 11.04; N, 3.07. Found: C, 68.24; H, 10.91; N, 3.20 .

(4R)-N,N-Dimethyl- $N$ - $\{[4$-(prop-1-en-2-yl)cyclohex-1en-1-yl]methyl hexadecylammonium Bromide (4e)

This salt was similarly prepared as the salt $4 \mathbf{a}$ as a wax $(0.388 \mathrm{~g}, 80 \%) .{ }^{1} \mathrm{H}$ NMR $\left(300 \mathrm{MHz}, \mathrm{CDCl}_{3}\right) \delta 6.32$ (s, 1H, H3), 4.77 (s, 1H, H9a), 4.69 (s, 1H, H9b), 4.28 (s, 2H, $\mathrm{H} 1), 3.52\left(\mathrm{~m}, 2 \mathrm{H}, \mathrm{CH}_{2} \mathrm{~N}\right), 3.31\left(\mathrm{~s}, 6 \mathrm{H}, \mathrm{Me}_{2} \mathrm{~N}\right), 2.38-2.23$ (m, $2 \mathrm{H}, \mathrm{H} 4), 2.23-2.05(\mathrm{~m}, 3 \mathrm{H}), 1.87-1.72(\mathrm{~m}, 2 \mathrm{H}), 1.74$ (s, 3H, H10), 1.58-1.47 (m, 1H), 1.40-1.20 (m, 27H), 0.88 (t, $J=6.6 \mathrm{~Hz}, 3 \mathrm{H}) \mathrm{ppm} ;{ }^{13} \mathrm{C}$ NMR $\left(75.5 \mathrm{MHz}, \mathrm{CDCl}_{3}\right) \delta$ $147.7,139.1,125.8,108.7,69.8,63.7,50.1,50.0,39.0,31.3$, 30.5, 29.1 (3C), 28.9, 28.9, 28.8, 28.7, 25.8, 22.4, 22.1, 20.2, 13.5; Anal. Calcd for $\mathrm{C}_{28} \mathrm{H}_{54} \mathrm{BrN}$ : C, 69.39; $\mathrm{H}, 11.23$; N, 2.89. Found: C, 69.30; H, 11.41; N, 2.78.

(4R)-N,N-Dimethyl- $N$ - $\{[4$-(prop-1-en-2-yl)cyclohex-1en-1-yl]methyl\}octylammonium Chloride (4f)

The flask was charged with 1-(chloromethyl)-4(prop-1-en-2-yl)cyclohexene $(2.0 \mathrm{~g}, 11.8 \mathrm{mmol})$ and 25 $\mathrm{mL}$ of anhydrous benzene. Anhydrous $\mathrm{N}, \mathrm{N}$-dimethyl- $N$-octylamine $(3.5 \mathrm{~mL}, 17.1 \mathrm{mmol})$ was then added. The reaction was carried out for 6 hours at reflux and stirred overnight at room temperature. The reaction mixture was evaporated in vacuo, benzene was added to dissolve the residue followed by diethyl ether. The product which separated in the refrigerator as a wax was dried in a vacuum desiccator over anhydrous $\mathrm{CaCl}_{2}$ to give the ammonium salt $(3.0 \mathrm{~g}, 87 \%) .{ }^{1} \mathrm{H}$ NMR $\left(300 \mathrm{MHz}, \mathrm{CDCl}_{3}\right) \delta 6.30(\mathrm{~s}$, 1H, H3), 4.76 (s, 1H, H9a), 4.69 (s, 1H, H9b), 4.29 (m, $2 \mathrm{H}), 3.50(\mathrm{~m}, 2 \mathrm{H}), 3.29\left(\mathrm{~s}, 6 \mathrm{H}, \mathrm{Me}_{2} \mathrm{~N}\right), 2.35-2.24(\mathrm{~m}, 2 \mathrm{H}$, H4), 2.24-2.03 (m, 3H), 1.86-1.70 (m, $2 \mathrm{H}), 1.73(\mathrm{~s}, 3 \mathrm{H}$, $\mathrm{H} 10), 1.58-1.46(\mathrm{~m}, 1 \mathrm{H}), 1.40-1.20(\mathrm{~m}, 11 \mathrm{H}), 0.88(\mathrm{t}, J=6$ $\left.\mathrm{Hz}, 3 \mathrm{H}, \mathrm{H}_{3} \mathrm{CCH}_{2}\right) ;{ }^{13} \mathrm{C}$ NMR $\left(75.5 \mathrm{MHz}, \mathrm{CDCl}_{3}\right) \delta 147.3$, 127.3, 125.5, 108.2, 69.3, 63.1, 49.6, 49.5, 39.6, 30.6, 30.1, 29.5, 28.1, 28.0, 26.3, 25.3, 21.9, 21.5, 19.7, 13.0; Anal. Calcd for $\mathrm{C}_{20} \mathrm{H}_{38} \mathrm{ClN}$ : C, 73.24; $\mathrm{H}, 11.68 ; \mathrm{N}, 4.27$. Found: $\mathrm{C}$, 73.41; H, 11.55; N, 4.09 .

(4R)- $N, N$-Dimethyl- $N$ - $\{[4$-(prop-1-en-2-yl)cyclohex-1en-1-yl]methyl\}decylammonium Chloride (4g)

This salt was similarly prepared as the salt $\mathbf{4 f}$ as a wax $(0.650 \mathrm{~g}, 70 \%) .{ }^{1} \mathrm{H}$ NMR $\left(300 \mathrm{MHz}, \mathrm{CDCl}_{3}\right) \delta 6.31(\mathrm{~s}, 1 \mathrm{H}$, H3), 4.76 (s, 1H, H9a), 4.69 (s, 1H, H9b), 4.27 (s, 2H, H1), $3.52\left(\mathrm{t}, J=8.1 \mathrm{~Hz}, 2 \mathrm{H}, \mathrm{CH}_{2} \mathrm{~N}\right), 3.31\left(\mathrm{~s}, 6 \mathrm{H}, \mathrm{Me}_{2} \mathrm{~N}\right), 2.38$ $2.03(\mathrm{~m}, 5 \mathrm{H}), 1.85-1.74(\mathrm{~m}, 3 \mathrm{H}), 1.74$ (s, 3H, H10), 1.45$1.10(\mathrm{~m}, 15 \mathrm{H}), 0.88(\mathrm{t}, J=6.9 \mathrm{~Hz}, 3 \mathrm{H}) ;{ }^{13} \mathrm{C}$ NMR $(75.5$ $\left.\mathrm{MHz}, \mathrm{CDCl}_{3}\right) \delta 147.7,138.9,125.8,108.7,69.8,63.6,49.9$, 49.9, 39.0, 31.2, 30.5, 29.9, 28.8 (2C), 28.6 (2C), 26.6, 25.8, 22.3, 22.0, 20.1, 13.5; Anal. Calcd for $\mathrm{C}_{22} \mathrm{H}_{42} \mathrm{ClN}$ : C, 74.22; H, 11.89; N, 3.93. Found: C, 74.03; H, 11.75; N, 4.08.

(4R)- $N, N$-Dimethyl- $N$ - $\{[4$-(prop-1-en-2-yl)cyclohex-1en-1-yl]methyl\}dodecylammonium Chloride (4h)

This salt was similarly prepared as the salt $\mathbf{4 f}$ as a wax (3.00 g, 73\%). ${ }^{1} \mathrm{H}$ NMR $\left(300 \mathrm{MHz}, \mathrm{CDCl}_{3}\right) \delta 6.29(\mathrm{~s}, 1 \mathrm{H}$, H3), 4.77 (s, 1H, H9a), 4,69 (s, 1H, H9b), 4.23 (s, 2H, H1), $3.48\left(\mathrm{~m}, 2 \mathrm{H}, \mathrm{CH}_{2} \mathrm{~N}\right), 3.30\left(\mathrm{~s}, 6 \mathrm{H}, \mathrm{Me}_{2} \mathrm{~N}\right), 2.38-2.25(\mathrm{~m}$, $2 \mathrm{H}, \mathrm{H} 4), 2.25-2.05(\mathrm{~m}, 3 \mathrm{H}), 1.87-1.72(\mathrm{~m}, 3 \mathrm{H}), 1.74(\mathrm{~s}$, $3 \mathrm{H}, \mathrm{H} 10), 1.58-1.45(\mathrm{~m}, 1 \mathrm{H}) 1.42-1.17(\mathrm{~m}, 18 \mathrm{H}), 0.88(\mathrm{t}, J$ $=6.6 \mathrm{~Hz}, 3 \mathrm{H}) ;{ }^{13} \mathrm{C} \mathrm{NMR}\left(75.5 \mathrm{MHz}, \mathrm{CDCl}_{3}\right) \delta 147.8,127.9$, $126.0,108.9,70.0,63.7,50.2,50.1,39.2,31.4,30.1,29.1$ (2C), 29.0, 29.0, 28.9, 28.8, 26.9, 25.9, 22.5, 22.2, 20.4, 20.3, 13.6; Anal. Calcd for $\mathrm{C}_{24} \mathrm{H}_{46} \mathrm{ClN}$ : C, 75.05; H, 12.07; N, 3.65. Found: C, $75.21 ; \mathrm{H}, 12.18$; N, 3.47 .

\section{3,7-Dimethyloct-6-en-7-yl Bromide (6)}

Bromide 6 was prepared by the published method from citronellol and its ${ }^{1} \mathrm{H}$ NMR spectrum was found to be identical with the one described. ${ }^{41}$

(3S)-N-Octyl- $N, N, 3,7$-tetramethyloct-6-en-1-ammonium Bromide (7a)

This salt was similarly prepared as the salt $\mathbf{4 a}$ as a wax $(0.338 \mathrm{~g}, 90 \%) .{ }^{1} \mathrm{H} \mathrm{NMR}\left(300 \mathrm{MHz}, \mathrm{CDCl}_{3}\right) \delta 5.06(\mathrm{~m}$, $1 \mathrm{H}, \mathrm{H} 6), 3.63-3.40\left(\mathrm{~m}, 4 \mathrm{H}, \mathrm{H1}, \mathrm{CH}_{2} \mathrm{~N}\right), 3.38(\mathrm{~s}, 6 \mathrm{H}$, $\left.\mathrm{Me}_{2} \mathrm{~N}\right), 2.07-1.93(\mathrm{~m}, 2 \mathrm{H}), 1.77-1.68(\mathrm{~m}, 3 \mathrm{H}), 1.68,(\mathrm{~s}$, $3 \mathrm{H}), 1.60(\mathrm{~s}, 3 \mathrm{H}), 1.60-1.56(\mathrm{~m}, 2 \mathrm{H}), 1.38-1.26(\mathrm{~m}, 14 \mathrm{H})$, $0.99(\mathrm{~d}, J=6.3 \mathrm{~Hz}, 3 \mathrm{H}), 0.88\left(\mathrm{t}, J=6.3 \mathrm{~Hz}, 3 \mathrm{H}, \mathrm{CH}_{3} \mathrm{CH}_{2}\right)$; ${ }^{13} \mathrm{C}$ NMR $\left(75.5 \mathrm{MHz}, \mathrm{CDCl}_{3}\right) \delta 31.2,123.7,63.5,62.3$, 
51.3, 51.2, 36.5, 31.1, 29.7, 29.5, 29.0, 28.8, 25.9, 25.7, 25.4, 23.5, 23.3, 19.4, 17.6, 14.0; Anal. Calcd for $\mathrm{C}_{20} \mathrm{H}_{42} \mathrm{BrN}$ : C, $63.81 ; \mathrm{H}, 11.25 ; \mathrm{N}, 3.72$. Found: C, 64.01; H, 11.37; N, 3.58.

\section{(3S)-N-Decyl- $N, N, 3,7$-tetramethyloct-6-en-1-ammoni-} um Bromide (7b)

This salt was similarly prepared as the salt $\mathbf{4 a}$ as a wax (0.343 g, 85\%). ${ }^{1} \mathrm{H}$ NMR (300 MHz, $\left.\mathrm{CDCl}_{3}\right) \delta 5.07$ (m, 1H, H6), 3.65-3.40 (m, 4H, H1, $\left.\mathrm{CH}_{2} \mathrm{~N}\right), 3.39(\mathrm{~s}, 6 \mathrm{H}$, $\left.\mathrm{Me}_{2} \mathrm{~N}\right), 1.99(\mathrm{~m}, 2 \mathrm{H}), 1.72(\mathrm{~m}, 3 \mathrm{H}), 1.68,(\mathrm{~s}, 3 \mathrm{H}), 1.60(\mathrm{~s}$, $3 \mathrm{H}), 1.60-1.56(\mathrm{~m}, 2 \mathrm{H}), 1.38-1.26(\mathrm{~m}, 18 \mathrm{H}), 0.99(\mathrm{~d}, J=$ $6.3 \mathrm{~Hz}, 3 \mathrm{H}), 0.88\left(\mathrm{t}, J=6.3 \mathrm{~Hz}, 3 \mathrm{H}, \mathrm{CH}_{3} \mathrm{CH}_{2}\right) ;{ }^{13} \mathrm{C} \mathrm{NMR}$ $\left(75.5 \mathrm{MHz} \mathrm{CDCl}_{3}\right) \delta 131.5,123.5,63.4,62.2,51.2,51.1$, $36.4,31.5,30.0,29.1$ (2C), 29.0, 28.9, 28.8, 26.3, 25.9, 25.4, 24.9, 22.4, 22.3, 19.0, 17.4, 13.7; Anal. Calcd for $\mathrm{C}_{22} \mathrm{H}_{46} \mathrm{BrN}$ : C, 65.32; H, 11.46; N, 3.46. Found: C, 65.49; $\mathrm{H}, 11.37$; N, 3.41.

(3S)- $N$-Dodecyl- $N, N, 3,7$-tetramethyloct-6-en-1-ammonium Bromide $(7 \mathrm{c})$

This salt was similarly prepared as the salt $\mathbf{4 a}$ as a wax (0.389 g, 90\%). ${ }^{1} \mathrm{H}$ NMR (300 MHz, $\left.\mathrm{CDCl}_{3}\right) \delta 5.06(\mathrm{~m}$, $1 \mathrm{H}, \mathrm{H} 6), 3.78-3.68\left(\mathrm{~m}, 4 \mathrm{H}, \mathrm{H1}, \mathrm{H} 1^{\mathrm{c}}\right), 3.39$ (s, 6H, $\left.\mathrm{Me}_{2} \mathrm{~N}\right)$, 2.06-1.93 (m, 2H), $1.68(\mathrm{~m}, 3 \mathrm{H}), 1.60(\mathrm{~s}, 3 \mathrm{H}), 1.60-1.56$ (m, 2H), $1.38-1.26(\mathrm{~m}, 20 \mathrm{H}), 1.00(\mathrm{~d}, J=6.3 \mathrm{~Hz}, 3 \mathrm{H}), 0.88$ $\left(\mathrm{t}, J=6.3 \mathrm{~Hz}, 3 \mathrm{H}, \mathrm{CH}_{3} \mathrm{CH}_{2}\right) ;{ }^{13} \mathrm{C} \mathrm{NMR}\left(75.5 \mathrm{MHz}, \mathrm{CDCl}_{3}\right)$ $\delta 131.7,123.6,63.6,62.4,51.3(2 \mathrm{C}), 36.6,30.2,29.4(2 \mathrm{C})$, 29.3, 29.3, 29.2, 29.0, 28.9, 26.0, 26.0, 25.5, 25.1, 22.6, 22.4, 19.1, 17.6, 13.9; Anal. Calcd for $\mathrm{C}_{24} \mathrm{H}_{50} \mathrm{BrN}$ : C, 66.64; $\mathrm{H}$, 11.65; N, 3.24. Found: C, 66.58; H, 11.79; N, 3.13.

(3S)- $N$-Tetradecyl- $N, N, 3,7$-tetramethyloct-6-en-1-ammonium Bromide ( $7 \mathrm{~d})$

This salt was similarly prepared as the salt $\mathbf{4 a}$ as a wax $(0.368 \mathrm{~g}, 80 \%) .{ }^{1} \mathrm{H} \mathrm{NMR}\left(300 \mathrm{MHz}, \mathrm{CDCl}_{3}\right) \delta 5.08(\mathrm{~m}$, $1 \mathrm{H}, \mathrm{H6}), 3.65-3.39\left(\mathrm{~m}, 4 \mathrm{H}, \mathrm{H1}, \mathrm{CH}_{2} \mathrm{~N}\right), 3.42(\mathrm{~s}, 6 \mathrm{H}$, $\left.\mathrm{Me}_{2} \mathrm{~N}\right), 2.05-1.94(\mathrm{~m}, 2 \mathrm{H}), 1.68(\mathrm{~m}, 3 \mathrm{H}), 1.61(\mathrm{~s}, 3 \mathrm{H})$, $1.66-1.58(\mathrm{~m}, 2 \mathrm{H}), 1.40-1.23(\mathrm{~m}, 24 \mathrm{H}), 0.99(\mathrm{~d}, J=6.3 \mathrm{~Hz}$, $3 \mathrm{H}), 0.88\left(\mathrm{t}, J=6.3 \mathrm{~Hz}, 3 \mathrm{H}, \mathrm{CH}_{3} \mathrm{CH}_{2}\right) ;{ }^{13} \mathrm{C} \mathrm{NMR}(75.5$ $\left.\mathrm{MHz}, \mathrm{CDCl}_{3}\right) \delta 131.9,123.7,63.6,62.5,51.4$ (2C), 36.7, $30.3,29.6,29.5,29.5,29.5,29.4$ (2C), 29.3, 29.3, 29.2, 29.1, 26.2, 25.6, 25.2, 22.7, 22.6, 19.3, 17.7, 14.0; Anal. Calcd for $\mathrm{C}_{26} \mathrm{H}_{54} \mathrm{BrN}$ : C, 67.80; H, 11.82; N, 3.04. Found: C, 67.61; $\mathrm{H}, 11.91 ; \mathrm{N}, 3.15$.

(3S)-N-Hexadecyl- $N, N, 3,7$-tetramethyloct-6-en-1-ammonium Bromide (7e)

This salt was similarly prepared as the salt $\mathbf{4 a}$ as a wax $(0.391 \mathrm{~g}, 80 \%) .{ }^{1} \mathrm{H}$ NMR $\left(300 \mathrm{MHz}, \mathrm{CDCl}_{3}\right) \delta 5.06(\mathrm{tt}$, $\left.J_{1}=6.9 \mathrm{~Hz}, J_{2}=1.5 \mathrm{~Hz}, 1 \mathrm{H}, \mathrm{H} 6\right), 3.63-3.44(\mathrm{~m}, 4 \mathrm{H}, \mathrm{H} 1$, $\left.\mathrm{CH}_{2} \mathrm{~N}\right), 3.41$ (s, 6H, $\mathrm{NMe}_{2}$ ), 2.05-1.88 (m, 2H), $1.69(\mathrm{~m}$, $3 \mathrm{H}), 1.60$ ( $\mathrm{s}, 3 \mathrm{H}), 1.66-1.52(\mathrm{~m}, 2 \mathrm{H}), 1.40-1.23(\mathrm{~m}, 28 \mathrm{H})$, $0.99(\mathrm{~d}, J=6.3 \mathrm{~Hz}, 3 \mathrm{H}), 0.88\left(\mathrm{t}, J=6.3 \mathrm{~Hz}, 3 \mathrm{H}, \mathrm{CH}_{3} \mathrm{CH}_{2}\right)$; ${ }^{13} \mathrm{C} \mathrm{NMR}\left(75.5 \mathrm{MHz}, \mathrm{CDCl}_{3}\right) \delta 131.9,123.7,63.7,62.5$, 51.3 (2C), 36.7, 30.3, 29.6, 29.6, 29.5, 29.4, 29.4, 29.4, 29.3, $29.3,29.3,29.1,29.0,26.1,25.6,25.2,24.8,22.7,22.6,19.2$,
17.7, 14.0; Anal. Calcd for $\mathrm{C}_{28} \mathrm{H}_{58} \mathrm{BrN}$ : C, 68.99; H, 11.90; N, 2.87. Found: C, 68.81; H, 11.90; N, 2.76.

\section{3,7-Dimethyloctadien-2,6-enyl Bromide (9)}

Bromide 9 was prepared by the published method from geraniol and its ${ }^{1} \mathrm{H}$ NMR spectrum was found to be identical with the one described. ${ }^{42}$

(2E)-N-Octyl- $N, N, 3,7$-tetramethylocta-2,6-dien-1-ammonium Bromide (10a)

This salt was similarly prepared from geraniol (8) as the salt 4a as a wax $(0.356 \mathrm{~g}, 95 \%) .{ }^{1} \mathrm{H}$ NMR $(300 \mathrm{MHz}$, $\left.\mathrm{CDCl}_{3}\right) \delta 5.32(\mathrm{t}, J=8.1 \mathrm{~Hz}, 1 \mathrm{H}, \mathrm{H} 2), 5.01(\mathrm{~m}, 1 \mathrm{H}, \mathrm{H} 6)$, $4.27(\mathrm{~d}, J=8.1 \mathrm{~Hz}, 2 \mathrm{H}, \mathrm{H} 1), 3.54-3.48\left(\mathrm{~m}, 2 \mathrm{H}, \mathrm{CH}_{2} \mathrm{~N}\right)$, $3.30\left(\mathrm{~s}, 6 \mathrm{H}, \mathrm{Me}_{2} \mathrm{~N}\right), 2.23-2.09(\mathrm{~m}, 4 \mathrm{H}, \mathrm{H} 4, \mathrm{H} 5), 1.90$ (s, $3 \mathrm{H}), 1.82-1.68(\mathrm{~m}, 2 \mathrm{H}), 1.68(\mathrm{~s}, 3 \mathrm{H}), 1.60$ (s, 3H), $1.42-$ $1.26(\mathrm{~m}, 10 \mathrm{H}), 0.88\left(\mathrm{t}, J=6.3 \mathrm{~Hz}, 3 \mathrm{H}, \mathrm{CH}_{3} \mathrm{CH}_{2}\right) ;{ }^{13} \mathrm{C}$ NMR $\left(75.5 \mathrm{MHz}, \mathrm{CDCl}_{3}\right) \delta 151.5,131.9,122.6,110.2$, $62.6,61.2,53.2,49.3$ (2C), 42.3, 39.5, 31.1, 28.6, 28.5, 25.8, 25,5, 25.2, 22.3, 22.0, 17.2, 17.2, 13.5; Anal. Calcd for $\mathrm{C}_{20} \mathrm{H}_{40} \mathrm{BrN}$ : C, 64.15; H, 10.77; N, 3.74. Found: C, 64.28; H, 10.89; N, 3.69.

(2E)-N-Decyl-N,N,3,7-tetramethylocta-2,6-dien-1-ammonium Bromide (10b)

This salt was similarly prepared as the salt $\mathbf{4 a}$ as a wax $(0.382 \mathrm{~g}, 95 \%) .{ }^{1} \mathrm{H} \mathrm{NMR}\left(300 \mathrm{MHz}, \mathrm{CDCl}_{3}\right) \delta 5.31(\mathrm{t}$, $J=8.1 \mathrm{~Hz}, 1 \mathrm{H}, \mathrm{H} 2), 5.02(\mathrm{~m}, 1 \mathrm{H}, \mathrm{H} 6), 4.26(\mathrm{~d}, J=8.1 \mathrm{~Hz}$, $2 \mathrm{H}, \mathrm{H} 1), 3.58-3.45\left(\mathrm{~m}, 2 \mathrm{H}, \mathrm{CH}_{2} \mathrm{~N}\right), 3.29\left(\mathrm{~s}, 6 \mathrm{H}, \mathrm{Me}_{2} \mathrm{~N}\right)$, 2.23-2.10 (m, 4H, H4, H5), 1.90 (s, 3H), 1.87-1.70 (m, $2 \mathrm{H}), 1.68(\mathrm{~s}, 3 \mathrm{H}), 1.60(\mathrm{~s}, 3 \mathrm{H}), 1.42-1.20(\mathrm{~m}, 14 \mathrm{H}), 0.88(\mathrm{t}$, $\left.J=6.3 \mathrm{~Hz}, 3 \mathrm{H}, \mathrm{CH}_{3} \mathrm{CH}_{2}\right) ;{ }^{13} \mathrm{C} \mathrm{NMR}\left(75.5 \mathrm{MHz}, \mathrm{CDCl}_{3}\right) \delta$ $151.1,131.5,122.3,109.9,62.3,60.8,56.9,53.0$ (2C), 48.9, 42.0, 39.1, 30.9, 28.5, 28.3, 25.5, 25.1, 24.9, 21.7, 16.9, 15.8, 13.2; Anal. Calcd for $\mathrm{C}_{22} \mathrm{H}_{44} \mathrm{BrN}$ : C, 65.65; H, 11.02; N, 3.48. Found: C, 65.51; H, 10.91; N, 3.34.

(2E)-N-Dodecyl- $N, N, 3,7$-tetramethylocta-2,6-dien-1-ammonium Bromide (10c)

This salt was similarly prepared as the salt $\mathbf{4 a}$ as a wax $(0.387 \mathrm{~g}, 90 \%) .{ }^{1} \mathrm{H}$ NMR $\left(300 \mathrm{MHz}, \mathrm{CDCl}_{3}\right) \delta 5.30(\mathrm{~m}$, $1 \mathrm{H}, \mathrm{H} 2), 5.00(\mathrm{~m}, 1 \mathrm{H}, \mathrm{H} 6), 4.22$ (d, $J=8.1 \mathrm{~Hz}, 2 \mathrm{H}, \mathrm{H} 1)$, $3.48-3.42\left(\mathrm{~m}, 2 \mathrm{H}, \mathrm{CH}_{2} \mathrm{~N}\right), 3.28\left(\mathrm{~s}, 6 \mathrm{H}, \mathrm{Me}_{2} \mathrm{~N}\right), 2.20-2.14$ (m, 2H), $1.90(\mathrm{~s}, 3 \mathrm{H}), 1.89-1.80(\mathrm{~m}, 2 \mathrm{H}), 1.68(\mathrm{~s}, 3 \mathrm{H}), 1.60$ (s, $3 \mathrm{H}), 1.43-1.22(\mathrm{~m}, 16 \mathrm{H}), 0.88\left(\mathrm{t}, J=6.3 \mathrm{~Hz}, \mathrm{CH}_{3} \mathrm{CH}_{2}\right)$; ${ }^{13} \mathrm{C} \mathrm{NMR}\left(75 \mathrm{MHz}, \mathrm{CDCl}_{3}\right) \delta 152.2,132.4,122.8,110.2$, 63.1, 61.6, 57.7, 53.3, 49.7, 42.6, 39.8, 31.6, 29.3, 29.3, 29.2, 29.1, 29.1, 28.8, 26.4, 24.1, 22.6, 17.6, 17.5, 13.9; Anal. Calcd for $\mathrm{C}_{24} \mathrm{H}_{48} \mathrm{BrN}$ : C, 65.65; H, 11.02; N, 3.48. Found: C, $65.51 ; \mathrm{H}, 10.91 ; \mathrm{N}, 3.33$.

(2E)-N-Tetradecyl- $N, N, 3,7$-tetramethylocta-2,6-dien-1-ammonium Bromide (10d)

This salt was similarly prepared as the salt $\mathbf{4 a}$ as a wax $(0.390 \mathrm{~g}, 85 \%) .{ }^{1} \mathrm{H} \mathrm{NMR}\left(300 \mathrm{MHz}, \mathrm{CDCl}_{3}\right) \delta 5.28(\mathrm{t}$, $J=7.8 \mathrm{~Hz}, 1 \mathrm{H}, \mathrm{H} 2), 5.01(\mathrm{~m}, 1 \mathrm{H}, \mathrm{H} 6), 4.26(\mathrm{~d}, J=8.1 \mathrm{~Hz}$, 
$2 \mathrm{H}, \mathrm{H1}), 3.52-3.44\left(\mathrm{~m}, 2 \mathrm{H}, \mathrm{CH}_{2} \mathrm{~N}\right), 3.31\left(\mathrm{~s}, 6 \mathrm{H}, \mathrm{Me}_{2} \mathrm{~N}\right)$, 2.20-2.14 (m, 2H), $1.90(\mathrm{~s}, 3 \mathrm{H}), 1.80-1.70(\mathrm{~m}, 2 \mathrm{H}), 1.68$ (s, $3 \mathrm{H}), 1.60(\mathrm{~s}, 3 \mathrm{H}), 1.43-1.22(\mathrm{~m}, 20 \mathrm{H}), 0.88(\mathrm{t}, J=6.3 \mathrm{~Hz}$, $\left.\mathrm{CH}_{3} \mathrm{CH}_{2}\right) ;{ }^{13} \mathrm{C}$ NMR $\left(75 \mathrm{MHz}, \mathrm{CDCl}_{3}\right) \delta 151.8,132.2$, $122.8,110.3,62.8,61.4,53.3$ (2C), 42.6, 39.7, 31.6, 29.3, 29.3 (2C), 29.2, 29.1, 29.0, 28.0, 29.9, 26.4, 24.1, 22.6, 17.6, 17.5, 13.9; Anal. Calcd for $\mathrm{C}_{26} \mathrm{H}_{52} \mathrm{BrN}$ : C, 68.09; H, 11.43; N, 3.05. Found: C, 68.30; H, 11.56; N, 2.92.

(2E)- $N$-Hexadecyl- $N, N, 3,7$-tetramethylocta-2,6-dien-1-ammonium Bromide (10e)

This salt was similarly prepared as the salt $\mathbf{4 a}$ as a wax $(0.389 \mathrm{~g}, 80 \%) .{ }^{1} \mathrm{H} \mathrm{NMR}\left(300 \mathrm{MHz}, \mathrm{CDCl}_{3}\right) \delta 5.30(\mathrm{t}$, $J=7.8 \mathrm{~Hz}, 1 \mathrm{H}, \mathrm{H} 2), 5.02(\mathrm{~m}, 1 \mathrm{H}, \mathrm{H} 6), 4.27(\mathrm{~d}, J=8.1 \mathrm{~Hz}$, $2 \mathrm{H}, \mathrm{H1}), 3.54-3.48\left(\mathrm{~m}, 2 \mathrm{H}, \mathrm{CH}_{2} \mathrm{~N}\right), 3.30\left(\mathrm{~s}, 6 \mathrm{H}, \mathrm{Me}_{2} \mathrm{~N}\right)$, 2.22-2.12 (m, 3H), $1.90(\mathrm{~s}, 3 \mathrm{H}), 1.84-1.70(\mathrm{~m}, 2 \mathrm{H}), 1.67$ (s, 3H), $1.60(\mathrm{~s}, 3 \mathrm{H}), 1.42-1.22(\mathrm{~m}, 24 \mathrm{H}), 0.88(\mathrm{t}, J=6.6$ $\left.\mathrm{Hz}, \mathrm{CH}_{3} \mathrm{CH}_{2}\right) ;{ }^{13} \mathrm{C} \mathrm{NMR}\left(\mathrm{CDCl}_{3}, 75 \mathrm{MHz}\right) \delta 151.3,131.7$, $122.5,110.1,62.5,61.0,53.1$ (2C), 42.2, 39.3, 31.1, 29.0 (2C), 29.0 (2C), 28.9, 28.8, 28.8, 28.7, 28.6, 25.7, 25.3, 25.1, 22.2, 22.0, 17.1, 17.1, 13.5; Anal. Calcd for $\mathrm{C}_{28} \mathrm{H}-$ ${ }_{56} \mathrm{BrN}$ : C, 69.10; H, 11.60; N, 2.88. Found: C, 69.28; H, $11.63 ; \mathrm{N}, 2.79$.

\section{3. Fungicidal Testing}

The compounds were screened in vitro for antifungal activity against the following five plant pathogens: Fusarium culmorum Sacc., Phytophthora cactorum Schroek, Alternaria alternata Keissl.(Fr.), Rhizoctonia solani Kuhn, and Botrytis cinerea Pers. Ex Fr and mold pathogens Chaetomium globosum Kunze, Aspergillus terreus Thom, Aspergillus niger Van Tieghem, and Penicillium ochrochloron Biourge. Pathogenic plant fungal strains came from the Institute of Plant Protection in Poznań, Poland and strains of mold fungi came from the Collection of Pure Cultures of Industrial Microbes of the Institute of Technology and Microbiology of the Faculty of Food Chemistry and Biotechnology of the Łódź University of Technology, Poland.

The test involved determination of mycelial growth retardation in agar medium: Potato Dextrose Agar (PDA; Difco) for phytopathogenic fungi and Sabouraud Dextrose Agar (SDA; Biocorp) for mold fungi. Stock solutions of test chemicals in acetone were added to agar medium to give a concentration of $200 \mathrm{mg} / \mathrm{L}$ (phytopathogenic fungi) and $10000 \mathrm{mg} / \mathrm{L}, 5000 \mathrm{mg} / \mathrm{L}, 2500 \mathrm{mg} / \mathrm{L}$ (mold fungi) and dispersed into sterile Petri dishes. Plates were inoculated within $24 \mathrm{~h}$ after they were poured. Four discs $(5 \mathrm{~mm}$ diameter) were cut from the margins of actively growing 2 week old colony and were placed in equal distances from each other on the surface of the solidified agar. PDA or SDA with addition of acetone was used as the negative control. The plates were incubated in the growth chamber at $25 \pm 1{ }^{\circ} \mathrm{C}$ (phytopathogenic fungi) and $28 \pm 1{ }^{\circ} \mathrm{C}$ (mold fungi). The radial growth of the fungal colonies was measured after 3-5 days depending on the growth rate of the control samples. The growth was determined by calculating the mean of two colony diameters of four replicate colonies. The fungicidal activity was expressed as the percentage of fungi growth inhibition compared to that of the untreated control. The relative growth inhibition of the treatment compared to the untreated control was calculated as percentage, using the following formula:

$$
\text { inhibition rate }(\%)=\frac{x-y}{x} \cdot 100
$$

where $x$ is fungal colony diameter on untreated PDA/SDA $(\mathrm{mm})$ and $y$ fungal colony diameter in treated PDA/SDA $(\mathrm{mm})$.

\section{4. Herbicidal Testing}

Studies on potential herbicidal activity were carried out in pot experiments under greenhouse conditions using the post-emergence tests (foliar application). As bioindicators, ten common species of weeds belonging to the monocotyledons and dicotyledons classes were used: Galium aparine, Polygonum nodosum, Papaver rhoeas, Apera spica-venti, Galinsoga parviflora, Chenopodium album, Plantago lanceolata, Brassica nigra, Amaranthus retroflexus, and Stelaria media. The dilutions of the tested compounds at the dose of $2 \mathrm{~kg} / \mathrm{ha}$ in the spray volume $500 \mathrm{~L} /$ ha were sprayed on approximately 2 -week seedlings of plants at the stage of two true leaves. Temperature during vegetation: night/day $15-25{ }^{\circ} \mathrm{C}$. The evaluation of the effects of the compounds was carried out separately for each plant species 2 weeks after the application, recording the degree of damage of the plants in percentage compared to the untreated control.

\section{Results and Discussion}

\section{1. Chemistry}

Synthesis of Perillyl Alcohol Derivatives with the Function of Ammonium Salt

The starting material in this synthesis was the reactive derivative of limonene - perillyl alcohol (1) which was
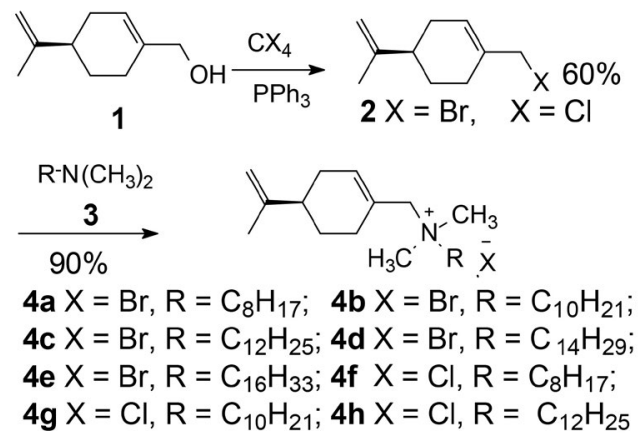

Scheme 1. The synthesis of perillyl ammonium salts $4 \mathbf{a}-\mathbf{h}$ 
converted to the bromine derivative 2 using carbon tetrabromide and triphenylphosphine, ${ }^{39}$ and to the chlorine derivative 3 using the classic Appel reaction conditions, i.e. carbon tetrachloride and triphenylphosphine in anhydrous DMF. ${ }^{40}$ The next step was alkylation by the resulting halides $\mathbf{2}$ and $\mathbf{3}$ of tertiary amines thus obtaining quaternary ammonium bromide salts $\mathbf{4 a}-\mathbf{e}$ and corresponding chlorides $\mathbf{4 f}-\mathbf{h}$ (Scheme 1).

\section{Synthesis of Citronellol Derivatives with the Function of Ammonium Salt}

The starting monoterpenoid cytronellol (5) occurs in nature and is used as repellent of mosquitoes and in perfumeries. Conversion to a bromine derivative $\mathbf{6}$ and alkylation of tertiary amines yielded five new quaternary ammonium salts $7 \mathbf{a}-\mathbf{e}$ (Scheme 2).
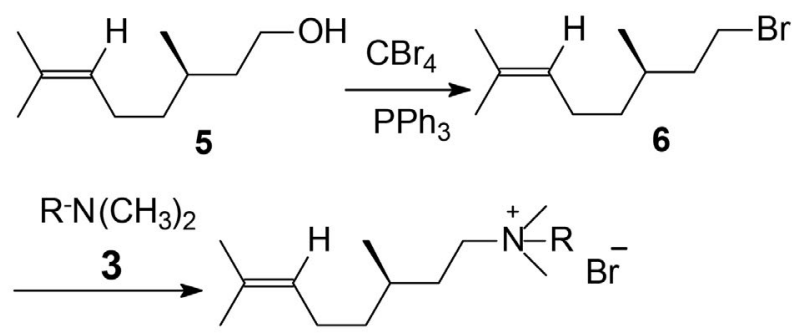

$7 \mathbf{a} \mathrm{R}=\mathrm{C}_{8} \mathrm{H}_{17} ; \mathbf{7 b} \mathrm{R}=\mathrm{C}_{10} \mathrm{H}_{21} ; \mathbf{7 c R}=\mathrm{C}_{12} \mathrm{H}_{25} ;$ 7d R $=\mathrm{C}_{14} \mathrm{H}_{29} ; 7 e \mathrm{R}=\mathrm{C}_{16} \mathrm{H}_{33}$

Scheme 2. The synthesis of cytronellyl ammonium salts $7 \mathbf{a}-\mathbf{e}$

\section{Synthesis of Geraniol Derivatives with the Function of Ammonium Salt}

Geraniol (8) is a component of essential oils of fruits and herbs with a broad spectrum of activity including repelling mosquitoes and chemoprevention of colon tumors. Analogously as described above, bromide 9 and five ammonium bromides 10a-e were obtained (Scheme 3).

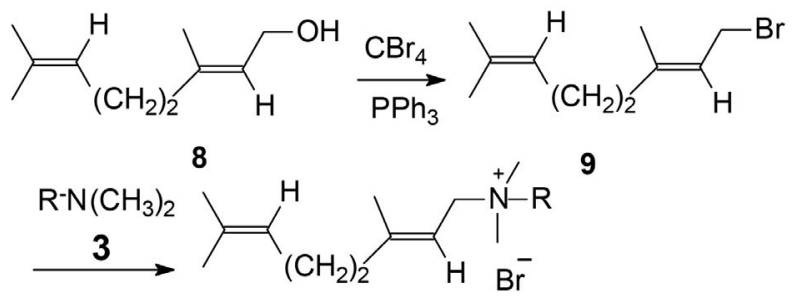

10a $\mathrm{R}=\mathrm{C}_{8} \mathrm{H}_{17} ; 10 \mathrm{~b} R=\mathrm{C}_{10} \mathrm{H}_{21} ; 10 \mathrm{c} \mathrm{R}=\mathrm{C}_{12} \mathrm{H}_{25}$;

10d $\mathrm{R}=\mathrm{C}_{14} \mathrm{H}_{29} ; 10$ e $\mathrm{R}=\mathrm{C}_{16} \mathrm{H}_{33}$

Scheme 3. The synthesis of geranyl ammonium salts 10a-e

\section{Antifungal Activity Assays of the Ammonium Salts}

Fungicidal activity of three sets of compounds: derivatives of perillyl alcohol (4a-h), citronellol ( $7 \mathbf{a}-\mathbf{e})$, and geraniol $(\mathbf{1 0 a}-\mathbf{e})$, was evaluated using in vitro poisoned food technique, assaying the degree of inhibition of mycelial growth on the agar medium at the basic concentration of $200 \mathrm{mg} / \mathrm{L}$. For the selected active compounds tests were also carried out at the concentration of $20 \mathrm{mg} / \mathrm{L}$. The following important phytopathogenic fungi were used for the biological assays: Alternaria alternata (A. a.), Botrytis cinerea (B. c.), Fusarium culmorum (F. c.), Phytophthora cactorum (Ph. c.), Phytophthora infestans (Ph. i.), and Rhizoctonia solani (Rh. s.).

The results of the first stage of screening tests revealed a good fungistatic effect of all quaternary salts at the concentration of 200 ppm against six tested pathogenic strains. It is worth noting that geranyl salts 10a-e exhibited $100 \%$ activity against $P h$. cactorum. The highest effectiveness-100\% inhibition of mycelial growth of five species of fungi-was shown for three compounds: $\mathbf{4 a}, \mathbf{4 b}$ (a derivative of perillyl alcohol with a C8 and C10 side chain) and 10a (a derivative of geraniol with a C8 side chain). As outlined in Table 1 the compounds possess more potent antifungal activities than commercial fungicides. Compound $\mathbf{4 b}$ showed also high activity at lower concentration of $20 \mathrm{ppm}$ against two fungal strains (B. cinerea and $\mathrm{Ph}$. cactorum).

Salts $4 a, 4 b, 4 g$ exhibited a broad spectrum antifungal activities against above mentioned phytopathogenic fungi, and showed more potent activities than the reference compound 11. Salts $7 \mathbf{b}-\mathbf{e}$ were more active than the reference compound $\mathbf{1 1}$ against two fungus strains and compounds 10a and 10b surpassed potency of the reference compound 12 against four fungus strains.

It is well known that biological activity of a molecule depends apart from electrophilic parameters on its lipophilicity. A majority of correlation between structure and different displays of biological activity reported in literature are ascribed mainly to hydrophobic-lipophilic character of substances. ${ }^{43,44}$ We have compared for the inspected compounds a fungistatic concentration and such lipophilic parameter of molecules as $\log P$ (partition coefficients $\mathrm{P}$ (n-octanol-water)).

The optimal range of $\log P$ values for the examined compounds was 3.2-4.4. It means that in the group of inspected compounds there is an optimal hydrophobic-hydrophilic character corresponding to salts with $\mathrm{C}_{8}-\mathrm{C}_{10}$ $\mathrm{N}$-substituent.

In another studies we used microorganisms Chaetomium globosum (C. g.) ŁOCK 0476, Aspergillus terreus (A. t.) ŁOCK 0451, Aspergillus niger (A. n.), and Penicillium ochrochloron (P. o.). These filamentous fungi are characterized by low nutritional requirements, they are easily spread in various environments and are responsible for biodeterioration of technical materials including lignocellulosic products. They represent types of filamentous fungi (Aspergillus, Penicillium, Chaetomium) capable of producing cellulase, an enzyme responsible, among others, for the decomposition of paper and wood. 
Table 1. Antifungal activity of compounds $4 \mathbf{a}-\mathbf{h}, 7 \mathbf{a}-\mathbf{e}$ and $10 a-e$ against plant pathogens in vitro at conc. $200 \mathrm{mg} / \mathrm{L}$

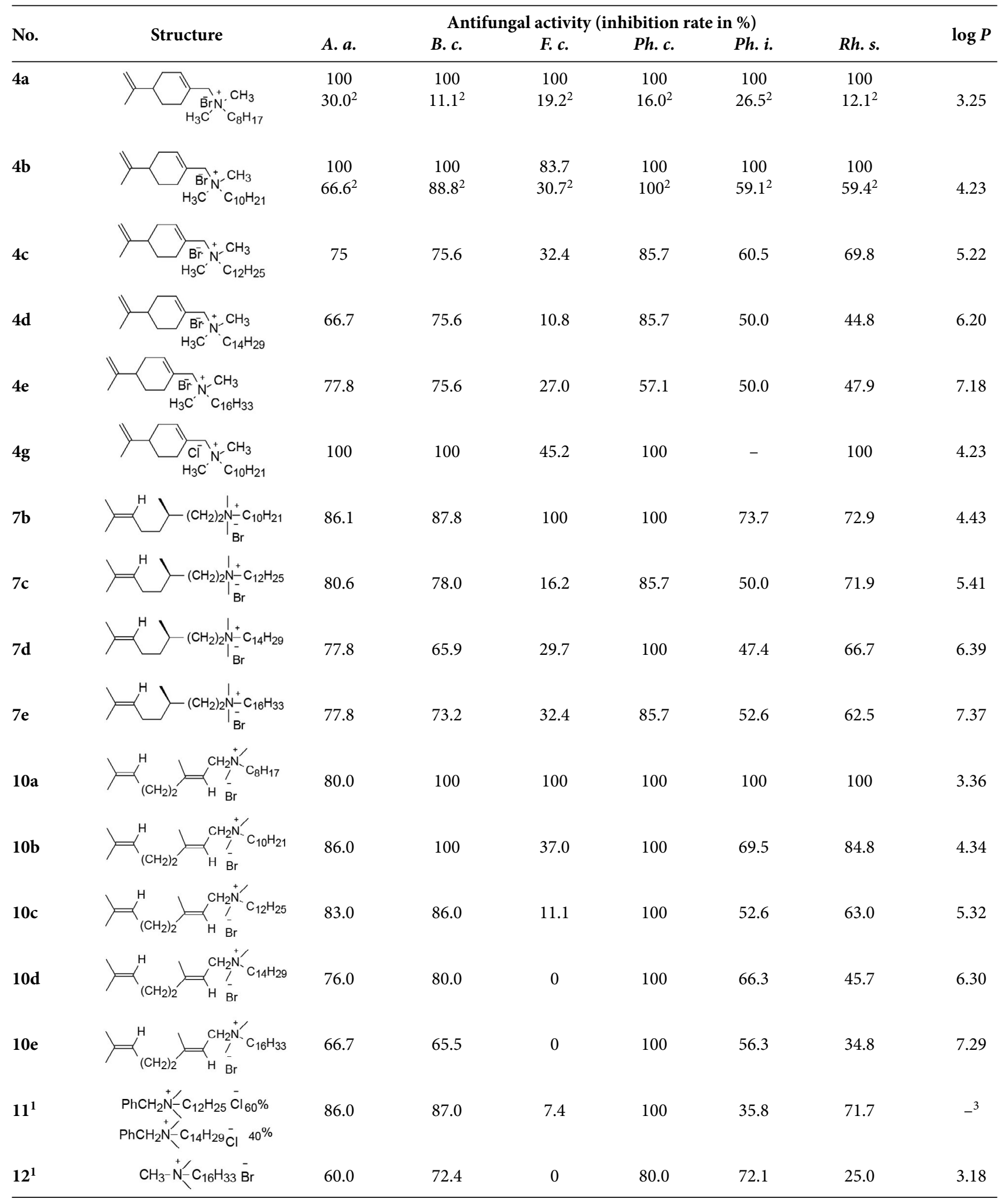

${ }^{1}$ Reference substance; ${ }^{2}$ values at a concentration of $20 \mathrm{mg} / \mathrm{L} ;{ }^{3} \log P$ for a mixture of two salts is not reliable.

The tested compounds showed very good activity against two strains of wood destroying fungi Chaetomium globosum and Penicillium ochrochloron. The salts $4 \mathbf{a}, 7 \mathbf{a}, 7 \mathbf{c}$ were particularly active against the two above strains, salt 
Table 2. Efficacy of test compounds $4 \mathbf{a}-\mathbf{h}, 7 \mathbf{a}-\mathbf{e}$ and 10a-e [\%] against fungi destroying wood and technical materials

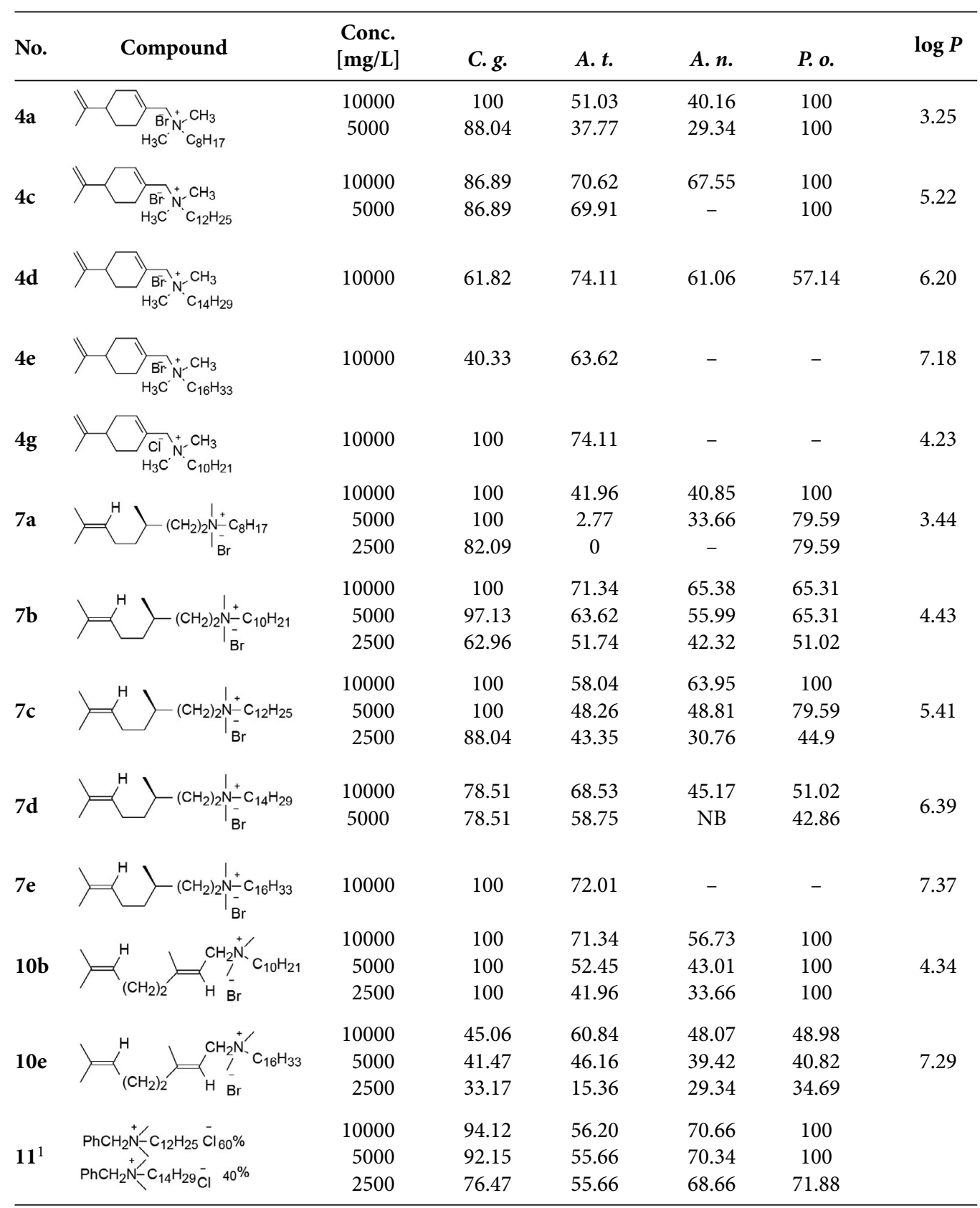

${ }^{1}$ Reference substance

4c against $P$. ochrochloron, and salts $7 \mathbf{b}$ and $7 \mathbf{e}$ against $C$. globosum. These were ammonium salts of perillyl alcohol (4a and $4 c)$ and citronellol (7a, $7 \mathbf{b}, 7 \mathbf{c}$ and $7 \mathbf{e})$.

Salts $4 \mathbf{a}, \mathbf{c}-\mathbf{e}$ were more active against one fungal strain than the reference compound, while salt $\mathbf{4 g}$ was more potent against Ch. globosum and A. tereus than reference compound 11. Salts $\mathbf{7 b}, \mathbf{7 c}$, and $\mathbf{7 d}$ were more active against two fungal strains than the reference compound 11, while salts $7 \mathbf{a}$ and $7 \mathrm{c}$ surpassed the activity of the reference compound against one fungal strain. Salt $\mathbf{1 0 b}$ was more active against two fungal strains (Ch. globosum and
A. tereus) than the reference compound $\mathbf{1 1}$ and salt $\mathbf{1 0 \mathrm { e }}$ was more active against one fungal strain (A. tereus) than the reference compound. The optimal range of $\log P$ values for the examined compounds was 3.2-5.4 corresponding to salts with $\mathrm{C}_{8}-\mathrm{C}_{12} \mathrm{~N}$-substituent.

Using the least squares linear regression method we have compared the activity of all the investigated compounds with their $\log P$ values. The comparison was done separately for the perillyl ammonium salts $(\mathbf{4 a}-\mathbf{g})$, citronellyl derivatives (7b-e), and geranyl derivatives (10a-e). For the set of the phytopathogenic fungi (Table 1) the ob- 
served activity for all the compounds apparently decreased with the increased length of an alkyl chain. On the other hand for the set of the fungi destroying wood and technical materials (Table 2) the dependence of the

Table 3. Herbicidal activity of quaternary ammonium salts $4 \mathbf{a}-\mathbf{h}, 7 \mathbf{a}-\mathbf{e}$ and $\mathbf{1 0 a}-\mathbf{e}$ (dose: $2 \mathrm{~kg} / \mathrm{ha})$

\begin{tabular}{|c|c|c|c|c|c|c|c|c|c|c|c|}
\hline No. & Compound & 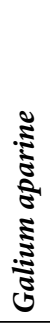 & 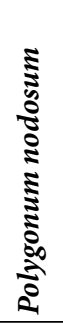 & 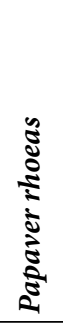 & 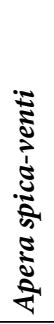 & 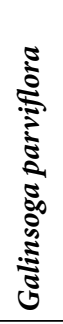 & 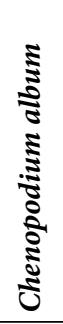 & 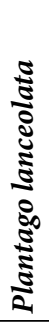 & 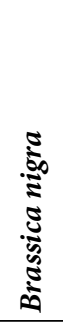 & 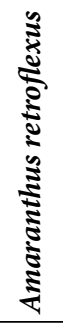 & 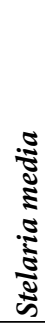 \\
\hline $4 a$ & $\mathrm{H}_{3} \mathrm{C} \quad \mathrm{C}_{8}$ & 70 & 100 & 100 & 20 & 70 & 100 & 20 & 70 & 100 & 70 \\
\hline $4 c$ & & 20 & 40 & 100 & 20 & 20 & 100 & 40 & 40 & 40 & 0 \\
\hline 4d & ${ }_{4} \mathrm{H}_{2}$ & 20 & 70 & 100 & 40 & 40 & 100 & 70 & 100 & 100 & 20 \\
\hline $4 e$ & & 20 & 40 & 100 & 40 & 70 & 100 & 70 & 100 & 70 & 0 \\
\hline $4 \mathrm{~g}$ & & 20 & 70 & 100 & 40 & 70 & 100 & 55 & 100 & 100 & 20 \\
\hline $7 \mathbf{b}$ & & 30 & 70 & 100 & 40 & 70 & 100 & 55 & 100 & 100 & 20 \\
\hline $7 c$ & & 30 & 100 & 100 & 70 & 100 & 100 & 70 & 100 & 100 & 20 \\
\hline $7 d$ & & 10 & 100 & 70 & 20 & 70 & 100 & 70 & 100 & 100 & 20 \\
\hline $7 e$ & & 40 & 100 & 100 & 70 & 100 & 100 & 70 & 100 & 100 & 40 \\
\hline $10 a$ & & 40 & 40 & 100 & 0 & 70 & 100 & 40 & 70 & 70 & 20 \\
\hline $10 b$ & & 20 & 20 & 40 & 0 & 20 & 20 & 20 & 20 & 20 & 20 \\
\hline $10 c$ & & 40 & 40 & 70 & 0 & 20 & 40 & 20 & 40 & 40 & 20 \\
\hline 10d & & 20 & 20 & 20 & 0 & 20 & 20 & 20 & 20 & 20 & 0 \\
\hline $10 e$ & & 20 & 20 & 40 & 0 & 20 & 40 & 20 & 20 & 20 & 0 \\
\hline $13^{1}$ & & 70 & 100 & 100 & 40 & 100 & 100 & 70 & 70 & 40 & 40 \\
\hline
\end{tabular}

\footnotetext{
${ }^{1}$ Reference substance phenmedipham
} 
activity on the length of an alkyl chain was not distinctly observed.

\section{Herbicidal Activity Assays}

Ten common species of weeds belonging to one monocot and nine dicot families were used as bioindicators for potential herbicidal activity testing: Galium aparine, Polygonum nodosum, Papaver rhoeas, Apera spica-venti, Galinsoga parviflora, Chenopodium album, Plantago lanceolata, Brassica nigra, Amaranthus retroflexus, and Stelaria media.

Most compounds showed herbicidal activity at the dose of $2 \mathrm{~kg} / \mathrm{ha}$ (via leaves), the weeds were destroyed in the range of 20 to $100 \%$ depending on the species (Table 3). The most active salts were derivatives of perillyl alcohol (with $\mathrm{C}_{8}-\mathrm{C}_{14}$ side chain) and derivatives of citronellol (with $\mathrm{C}_{10}-\mathrm{C}_{16}$ side chain), where two salts showed $100 \%$ activity against six weeds and two salts showed $100 \%$ activity against four weeds. High activity of all perillyl salts 4a-h against two species Papaver rhoeas and Chenopodium album was found. Compound $\mathbf{4 a}$ with the shortest side chain was the most active against weeds Galium aparine and Polygonum nodosum. For Galinsoga parviflora a parabolic dependence was observed with the lowest activity for $\mathrm{C}_{12}-\mathrm{C}_{14}$ derivatives and a higher potency for $\mathrm{C}_{8}$ and $\mathrm{C}_{16}$ salts. On the other hand for weeds Plantago lanceolata and Brassica nigra the highest activity was noticed for a long chain $\mathrm{C}_{14}$ and $\mathrm{C}_{16}$ ammonium bromides. A higher activity of the tested compounds than one of the reference compound $\mathbf{1 3}$ was shown by salts $\mathbf{4 d - g}$ against weed Plantago lanceolata, by compounds $\mathbf{4 a}, \mathbf{4 d}$, and $\mathbf{4 g}$ against Amaranthus retroflexus, and compound 4 a against Stelaria media.

High activity of all citronellyl salts $7 \mathbf{b}-\mathbf{e}$ against three herbs Chenopodium album, Brassica nigra and Amaranthus retroflexus was found. Again higher activity than potency of the reference compound was noticed for salts $7 \mathrm{c}$ and $7 \mathbf{e}$ against monocot species Apera spica-venti, for salts 7b-e against weeds Brassica nigra and Amaranthus retroflexus.

In case of geranyl derivatives 10a-e the highest activity of $\mathrm{C}_{8}$ salt was found against all weeds. Salt $10 \mathrm{~b}$ was more potent against Amaranthus retroflexus than the reference compound.

\section{Conclusions}

Eighteen novel quaternary ammonium salts (QASs) with a terpenoid moiety have been synthesized. Most compounds showed a broad spectrum of biological activity including both fungistatic and herbicidal activity. A favourable effect of terpene group introduction was shown by a higher potency of many synthesized salts than that of reference compound 11 and $\mathbf{1 2}$ being pure quaternary alkylammonium compounds. Some dependence of fungistatic activity on $\log P$ was demonstrated.

\section{Acknowledgements}

This work was supported in part by the Polish Ministry of Science and Higher Education (Research Grant NR EMC: $0 / 17 / 005 / \mathrm{K}$ ), which is gratefully acknowledged.

Conflict of Interest: The authors declare that they have no conflict of interest.

\section{References}

1. P. P. Raichurkar, V. G. Nadiger, T. Ranjit, G. S. Nadiger, Colourage 2017, 64, 43-51.

2. S. Zhang, X. Yang, B. Tang, L. Yuan, K. Wang, X. Liu, X. Zhu, J. Li, Z. Ge, Chem. Eng. J. 2018, 336, 123-132.

3. K. Rajkowska, A. Koziróg, A. Otlewska A, M. Piotrowska, P. Nowicka-Krawczyk, B. Brycki, A. Kunicka-Styczyńska, B. Gutarowska, Acta Biochim. Pol. 2016, 63, 153-159.

4. N. N. D. Daoud, N. N. Dickinson, P. Gilbert, Microbios 1983, 37, 75-85.

5. B. Brycki, A. Koziróg, I. Kowalczyk, T. Pospieszny, P. Materna, J. Marciniak, Molecules 2017, 22, 1810.

DOI:10.3390/molecules22111810

6. M. Tischer, G. Pradel, K. Ohlsen, U. Holzgrabe, Chem. Med. Chem. 2012, 7, 22-31. DOI:10.1002/cmdc.201100404

7. J. Zabielska-Matejuk, K. Czaczyk, Wood Sci. Technol. 2006, 40, 461-475. DOI:10.1007/s00226-005-0065-2

8. B. Brycki, I. Małecka, A. Koziróg, A. Otlewska, Molecules 2017, 22, 130. DOI:10.3390/molecules22010130

9. Y. Yang, V. Reipa, G. Liu, Y. Meng, X. Wang, K. P. Mineart, V. M. Prabhu, W. Shi, N. J. Lin, X. He, J. Sun, ACS Appl. Mater. Interfac. 2018, 10, 8566-8573. DOI:10.1021/acsami.8b01089

10. E. A. Chugunova, N. I. Akylbekov, E. M. Mahrous, A. D. Voloshina, N. V. Kulik, V. V. Zobov, A. G. Strelnik, T. P. Gerasimova, A. B. Dobrynin, A. R. Burilov, Monatsh. Chem. 2018, 149, 119-126. DOI:10.1007/s00706-017-2052-3

11. W. Seebacher, F. Belaj, J. Faist, R. Saf, F. Bucar, I. Turek, A. Brantner, M. Alajlani, M. Kaiser, P. Mäser, R. Weis, Monatsh. Chem. 2017, 148, 263-274. DOI:10.1007/s00706-016-1864-x

12. E. Obłąk, A. Piecuch, J. Rewak-Soroczyńska, E. Paluch, Appl. Microbiol. Biotechnol. 2018, 1-8.

13. S. Q. Fu, J. W. Guo, X. Zhong, Z. Yang, X. F. Lai, RSC Advances, 2016, 6, 16507-16515.

14. C. Zhang, Y. Jiang, H. Ju, Y. Wang, T. Geng, J. Mol. Liquids 2017, 241, 638-645. DOI:10.1016/j.molliq.2017.06.062

15. B. Brycki, H. Koenig, T. Pospieszny, Molecules 2015, 20, 20887-20900. DOI:10.3390/molecules201119735

16. G. De Luca, R. Amuso, A. Figoli, R. Mancuso, L. Lucadamo, B. Gabriele, Appl. Sci. (Switzerland) 2018, 8, 1972.

17. A. Madhusudhan Reddy, P. Srinivasa Babu, Research J. Pharm. Technol. 2016, 9, 322-332.

DOI:10.5958/0974-360X.2016.00058.5

18. F. Demirci, K. Yildirim, H. B. Kocer, J. Appl. Polym. Sci. 2018, 135, 45914. DOI:10.1002/app.45914

19. J. Hoque, V. Yadav, R. G. Prakash, K. Sanyal, J. Haldar, ACS Biomaterials Sci. Engineer. 2019, 5, 81-91. 
20. M. Stasiewicz, A. Fojutowski, A. Kropacz, J. Pernak, Holzforschung 2008, 62, 309-317. DOI:10.1515/HF.2008.028

21. J. Pernak, J. Zabielska-Matejuk, A. Kropacz, J. Foksowicz-Flaczyk, Holzforschung 2004, 58, 286-291.

22. J. Zabielska-Matejuk, A. Stangierska, M. Kot, J. Wood Chem Technol. 2015, 35, 178-192.

DOI:10.1080/02773813.2014.909852

23. E. A. Courtois, C. Baraloto, C. E. T. Paine, P. Petronelli, P.-A. Blandinieres, D. Stien, E. Höuel, J.-M.Bessire, J. Chave, Phytochemistry 2012, 82, 81-88.

DOI:10.1016/j.phytochem.2012.07.003

24. A. A. Santos, B. M. S. de Oliveira, C. R. Melo, A. P. S. Lima, E. D. R. Santana, A. F. Blank, M. C. Picanço, A. P. A Araújo, P. F. Cristaldo, L. Bacci, Ecotox. Environ. Safety 2017, 145, 436-441. DOI:10.1016/j.ecoenv.2017.07.057

25. Y. Xie, M. Li, Q. Huang, C. Lei, Nat. Prod. Commun. 2014, 9, 719-722.

26. F. S. Nakayama, Industr. Crops Prod. 2005, 22, 3-13. DOI:10.1016/j.indcrop.2004.05.006

27. F. Xu 2008. In: B. G. Zhao, K. Futai, J. R. Sutherland, Y. Takeuchi (Eds: Pine Wilt Disease, Springer, Japan, p 323.

28. J. Hu, Y. Shen, S. Pang, Y. Gao, G. Xiao, S. Li, Y. Xu, J. Environ. Sci. (China) 2013, 25(S1), S32-S35.

29. C.-L. Ho, P.-C. Liao, E. I.-C. Wang, Y.-C. Su, Nat. Prod. Commun. 2011, 6, 1755-1758.

30. P. Makvandi, R. Jamaledin, M. Jabbari, N. Nikfarjam, A. Borzacchiello, Dental Mater. 2018, 34, 851-867.

31. K. Michalíková, L. Linhartová, M. Ezechiáš, T. Cajthaml, Chemosphere 2019, 534-541.

DOI:10.1016/j.chemosphere.2018.11.006

32. E. Novotná, K. Waisser, J. Kuneš, K. Palát, V. Buchta, J. Stolaříková, R. Beckert, V. Wsõl, Arch. Pharm. 2014, 347, 381-386. DOI:10.1002/ardp.201300407
33 G. Liu, G. Wu, C. Jin, Z. Kong, Progr. Org. Coatings 2015, 80, 150-155. DOI:10.1016/j.porgcoat.2014.12.005

34. A. H. Khan, E. Topp., A. Scott., M. Sumarah, S. M. Macfie, M. B. Ray, J. Hazard. Mater. 2015, 299, 595-602.

35. Q. Wu, C. Liu, J. Yang, A. Guan, H. Ma, Pestic. Biochem. Phys. 2017, 143, 246-251. DOI:10.1016/j.pestbp.2017.05.006

36. B. Souyei, A. H. Seyd, F. Zaiz, A. Rebiai, Acta Chim. Slov. 2019, 66, 315-325. DOI:10.17344/acsi.2018.4793

37. L. Antypenko, F. Meyer, Z. Sadykova, L.- A. Garbe, K. Steffens, Acta Chim. Slov. 2018, 65, 836-841.

DOI:10.17344/acsi.2018.4440

38. W.M. Gołębiewski, M. Gucma, K. Żelechowski, M. Krawczyk, A. Michalczyk 2018, Pochodne czwartorzędowych soli amoniowych $\mathrm{z}$ funkcją terpenową i ich zastosowanie. Pl Patent Application 425314, April 04, 2018.

39. A. F. Barrero, M. M. Herrador, J. F. Quílez del Moral, P. Arteaga, J. F. Arteaga, H. R. Diéguez, E. M. Sánchez, J. Org. Chem. 2007, 72, 2988-2995. DOI:10.1021/jo062630a

40. M. Longhi, S. Arnaboldi, E. Husanu, S. Grecchi, I. F.Buzzi, R. Cirilli, S. Rizzo, C. Chiappe, P. R. Mussini, Electrochim. Acta 2019, 298, 194-209. DOI:10.1016/j.electacta.2018.12.060

41. S. Sankaranarayanan, A. Sharma, S. Chattopadhyay, Tetrahedr. Asymm. 2002, 13, 1373-1378.

42. S. Combemale, J.-N. Assam-Evoung, S. Houaidji, R. Bibi, V. Barragan-Montero, Molecules 2014, 19, 1120-1149.

DOI:10.3390/molecules 19011120

43. M. Mellado, A. Madrid, M. Reyna, C. Weinstein-Oppenheimer, J. Mella, C. O. Salas, E. Sánchez E, M. Cuella, Med. Chem. Res. 2018, 27, 2414-2425. DOI:10.1007/s00044-018-2245-2

44. S. Combemale, J.-N. Assam-Evoung, S. Houaidji, R. Bibi, V. Barragan-Montero, Molecules 2014, 19, 1120-1149. DOI:10.3390/molecules 19011120

\section{Povzetek}

Sintetizirali smo serijo novih kvarternih amonijevih soli (QAS), katerih terpenoidni fragment izvira iz perilil alkohola, citronelola in geraniola. Strukture novih spojin smo potrdili s spektroskopskimi metodami in z elementno analizo. Fungicidno aktivnost pripravljenih spojin smo preučili na šestih rastlinskih patogenih organizmih, štirih glivah, ki uničujejo les in druge tehnične materiale; herbicidno aktivnost pa smo raziskali na desetih vrstah plevelov, ki uspevajo v pasu zmernega podnebja. Nekaj pripravljenih soli je izkazalo višjo aktivnost proti glivam in herbicidno aktivnost kot so bile ugotovljene za referenčne spojine.

Except when otherwise noted, articles in this journal are published under the terms and conditions of the Creative Commons Attribution 4.0 International License 